\title{
Pelatihan Robot Line Follower Di Pesantren Asshiddiqiyah 2 Batu Ceper
}

\author{
Andi Junaidi'; M. Imbarothur Mowaviq ${ }^{2}$; Rizki Pratama Putra ${ }^{3}$; Rudina Okvasari ${ }^{4}$ \\ 1, 2, 3, 4 Institut Teknologi PLN \\ Program Studi Teknik Elektro, Departemen Elektro \\ ${ }^{1}$ andi.junaidi@itpln.ac.id \\ 2 mowaviq@itpln.ac.id \\ ${ }^{3}$ rizki@itpln.ac.id \\ ${ }^{4}$ rudina@itpln.ac.id
}

\begin{abstract}
Science in the field of technology and information continues to grow rapidly. One of them is in the field of robotic systems. In Indonesia, especially Islamic boarding schools very few include extracurricular subjects or activities on robotics at both the high school and vocational level. This could be because it has not been directed and given a policy from the Ministry of Education to be given basic robotics lessons. Asshiddiqiyah Islamic Boarding School Batuceper Tangerang is one of the pesantren that has consistently provided Education and through this community service students are expected to receive training and experience to support new knowledge in technology one of which is basic robot training. Type of robot that we will use is line follower robot. Expected outputs in this community service are robotic system training, robot line follower contest as a benchmark for training results for Asshiddiqiyah high school students.
\end{abstract}

Keywords: Training, Robot line follower, Pesantren

\begin{abstract}
ABSTRAK
Ilmu pengetahuan dibidang teknologi dan informasi terus berkembang pesat belakangan ini. Salah satunya adalah dibidang robotic system. Di Indonesia sendiri khususnya pondok pesantren sangat sedikit memasukkan matapelajaran atau kegiatan ekstrakulikuler tentang robotik ini baik di tingkat SMA maupun SMK. Hal ini bisa dikarenakan belum diarahkan dan diberi kebijakan dari kementrian Pendidikan untuk diberikan pelajaran robotik dasar. Pondok Pesantren Asshiddiqiyah 2 Batuceper Tangerang merupakan salah satu pesantren yang selama ini konsisten memberikan Pendidikan dan melalui pengabdian masyarakat ini para santri diharapkan mendapatkan pelatihan dan pengalaman guna menunjang ilmu yang baru dibidang teknologi salah satunya adalah pelatihan robot dasar. Dimana jenis robot yang akan kita gunakan adalah robot line follower. Luaran yang diharapkan dalam kegiatan pengabdian ini adalah pemahaman tentang robotic system dan lomba robot line follower sebagai tolok ukur hasil pelatihan untuk santri SMA Manba'ul ulum Asshiddiqiyah 2.
\end{abstract}

Kata kunci: Pelatihan, Robot line follower, Pesantren 


\section{PENDAHULUAN}

Perkembangan pendidikan pesantren ditengah kemajuan teknologi dan informasi dapat memberikan warna terhadap keberadaan pondok pesantren di Indonesia yang dinilai sangat terbelakang dalam hal informasi, khususnya dalam pemanfaatan teknologi dan informasi dalam pengelolaan pendidikan. Oleh karena itu, maka keberadaan pendidikan pesantren dilihat dari sejarahnya sampai sekarang banyak mengalami perubahan di dalam penegambangan keilmuan baik dalam hal agama ataupun pengetahuan umum.

Sejalan dengan UU siskdiknas No 20 tahun 2003 pasal 30 ayat 4, dapat memberikan angin segar dan menghilangkan adanya diskriminasi bagi pesantren dalam hal pengembangan pendidikan agama [1]. karena selama ini pesantren diklaim sebagai lembaga yang konsen di dalam pengajaran ke agamaan. Disamping itu, pula dengan kemajuan zaman dimana pemanfaat teknologi informasi di lembaga pendidikan bukanlah sesuatu yang baru. maka agar dapat mengangkat keberadaan pesantren ditengah kemajuan ini dunia pesantren sebagai lembaga pendidikan harus selalu mengupdate informasi-nformasi yang mereka pergunakan. Selain itu dengan teknologi informasi pesantren dapat terbantu dalam melakukan penyebaran informasi mengenai profil, kegiatan dan menegemen pesantren dalam pengembangan pendidikan.

Tuntutan yang memang mau tidak mau akan dihadapi oleh dunia pendidikan adalah perkembangan jaman dimana teknologi informasi akan terus menerus berkembang, generasi kedepan akan sangat dituntut untuk menguasia bidang bidang tersebut dan terbiasa menggunakan fasilitas fasilitas tersebut yang nantinya akan menjadi media pembelajaran

Ilmu pengetahuan dibidang teknologi dan informasi terus berkembang pesat belakangan ini. Salah satunya adalah dibidang robotic system. Di Indonesia sendiri khususnya pondok pesantren sangat sedikit memasukkan matapelajaran dan kegiatan ekstrakulikuler tentang robotik ini baik di tingkat SMA maupun SMK. Hal ini bisa dikarenakan belum diarahkan dan diberi kebijakan dari kementrian Pendidikan untuk diberikan pelajaran robotik dasar.

Kegiatan yang akan dilaksanakan ini adalah kegiatan pelatihan yang di pelopori oleh dosendosen elektro dan mahasiswa IT-PLN guna memperkenalkan dan mengajarkan santriwan dan santriwati pondok pesantren asshiddiqiyah tentang sistem robotik, secara khusus line follower robot.

Robot merupakan salah satu perkembangan teknologi yang saat ini berkembang dalam dunia khususnya di Indonesia [2]. Robot line follower adalah sebuah robot yang dapat mengikuti garis secara otomatis. Robot line follower berbasis mikrokontroler dirancang dan dibuat agar dapat melakukan fungsi berjalan mengikuti garis yang berwarna hitam [3]. Basis penglihatan robot adalah rangkaian sensor garis yang tersusun dari LED-Photodiode, sedangkan gerakan robot ditopang oleh dua buah motor DC [4]. Instruksi AVR diputar untuk mengurangi ukuran program apakah kode ditulis dalam $\mathrm{C}$ atau bahasa assembly. Dengan on-chip, Flash dan program dalam system EEPROM, AVR adalah pilihan yang tepat dalam mengoptimalkan biaya[5,6]. Pilihan kita tergantung pada robot fungsi, daya dan presisi. Salah satu cara agar robot berjalan dengan baik adalah memilih motor yang bagus [7]. Jarak antara sensor dan permukaan tanah harus 3 atau $2 \mathrm{~mm}$ dan jarak antara masingmasing sensor tergantung pada lebar garis [8]. Pengendalian kecepatan sangat bergantung pada batas putaran dan pergesekan antara ban robot dengan lantainya. Robot tersebut dirancang untuk bernavigasi dan bergerak secara otomatis mengikuti sebuah alur garis yang dibua untuk membaca garis, robot dilengkapi dengan sensor yang diletakkkan diujung depan dari robot tersebut. Robot line follower ini memiliki jenis dan bentuk serta memiliki beberapa sistem penggerak dan pengendali sebagai pengatur kinerja yang beraneka ragam sesuai dengan kreatifitas dalam pembuatannya. 


\section{METODE/PERANCANGAN KEGIATAN}

Pelatihan robot line follower ini bertujuan untuk memperkenalkan teknologi mikrokontroler sebagai penunjang dalam peningkatan keterampilan siswa SMA Manbaul Ulum Asshiddiqiyah 2 dalam hal elektronika dan aplikasinya. Pelatihann tersebut akan dilakukan dalam 3 hari pelatihan yang akan diikuti oleh 30 siswa. Hari pertama akan digunakan untuk pemaparan mengenai teori dasar Arduino dan aplikasi sederhana melalui pengontrolan lampu LED, kemudian dihari berikutnya adalah pembuatan dan pemrograman robot line follower dan hari terakhir siswa mengikuti perlombaan robot line follower yang telah mereka rangkai dan program secara mandiri.

Instrumen yang digunakan dalam pelatihan adalah dengan instrumen pembuatan rancang bangun robot line follower, unjuk kerja robot line follower menggunakan arduino, kelayakan penggunaan media dalam pembelajaran rancang bangun dan unjuk kerja robot beroda otomatis. Instrumen pembuatan rancang-bangun robot line follower meliputi komponen penyusun rangkaian robot line follower, seperti sensor garis, driver motor, baterai serta peralatan lain yang digunakan dalam pembuatan robot line follower.

Kegiatan Pengabdian Kepada Masyarakat (PKM) ini dilaksanakan dengan melalui beberapa tahapan. Tahapan yang akan dilaksanakan dapat dilihat pada diagram alir pada gambar 3.1. Dimana kegiatan ini dimulai dengan persiapan dan koordinasi dengan pihak sekolah. Kemudian dilanjutkan dengan pembuatan modul pelatihan robot line follower. Pada hari pelaksanaan kegiatan siswa diajarakan tentang komponen komponen elektronika untuk membangun suatu robot sederhana. Pada akhirnya kita coba untuk melombakan robot yang telah dibuat sebagai salah satu bahan evaluasi tentang seberapa dalam pemahaman yang telah diterima oleh para santri.

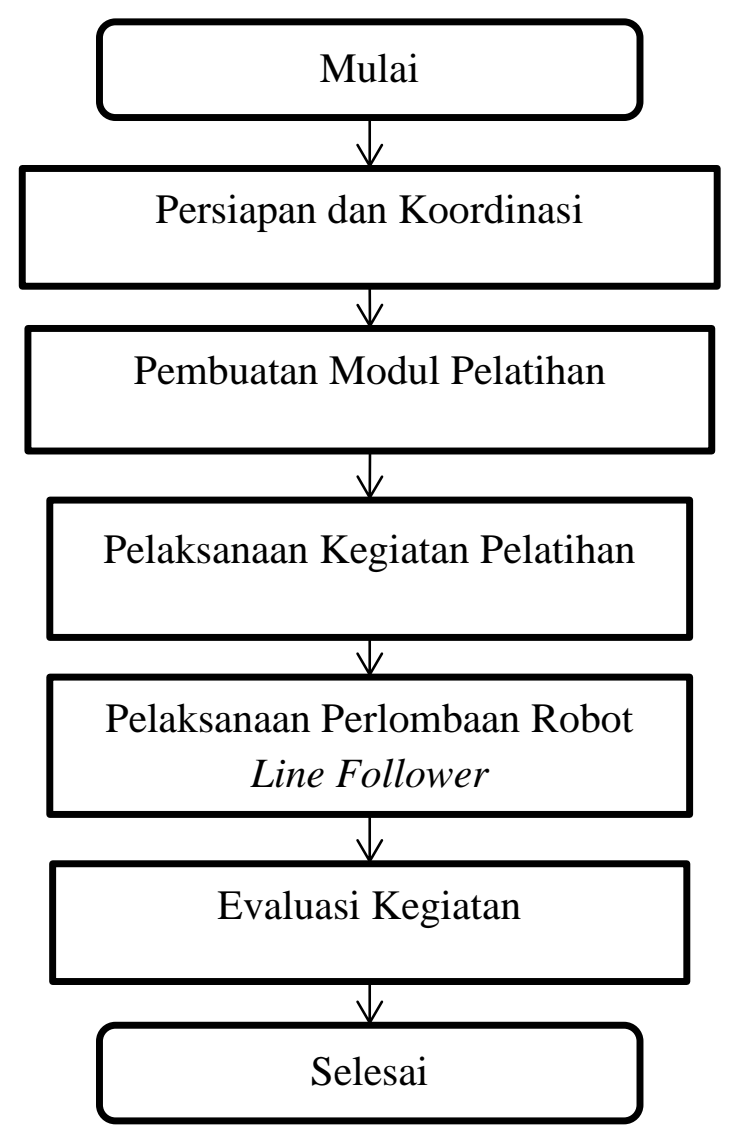

Gambar 1. Diagram Alir Pelaksanaan Pengabdian 
Agenda di yang lebih rinci dalam pelatihan aplikasi mikrokontroler dengan menggunakan arduino adalah sebagai berikut:

\section{Hari Pertama Pengenalan Arduino}

a) Langkah 1: peserta dikenalkan komponen-komponen elektronika dan cara kerjanya

b) Langkah 2: Peserta belajar merangkai pada breadboard yang menjadi objek untuk simulasi pengontrolan lampu LED

c) Langkah 3: peserta di kenalkan program Arduino dan tool-tool yang digunakan dalam pelatihan

d) Langkah 4: Peserta diajarkan mengimport program yang telah dibuat ke dalam Arduino sehingga didapatkan pengendalian lampu LED sesuai yang kita inginkan

\section{Hari kedua Pelatihan Robot Line Follower}

a) Langkah 1: Peserta di kenalkan robotic system dan komponen apa saja yang akan digunakan dalam membangun sebuah robot line follower

b) Langkah 2: Peserta merangkai komponen robot dan memprogramnya.

c) Langkah 3: setelah merangkai dan upload program, peserta pelatihan mencoba robot hasil karyanya di jalur robot yang telah dibuat.

d) Langkah 4: Setelah penyampaian materi, dilakukan diskusi dan tanya jawab tentang materi yang telah disampaikan.

e) Langkah 5: Peserta diberikan pertanyaan untuk menegtahui seberapa dalam pengetahuan yang telah di dapatkan siswa dan diberikan doorprize bagi yang bisa menjawab dengan benar.

\section{Hari ketiga Lomba Robot Line Follower}

a) Langkah 1: Peserta di kondisikan agar mengecek kembali kesiapan robot yang telah mereka buat dan memperbaiki apabila ada program atau rangkaian yang kurang sempurna.

b) Langkah 2: Peserta mengambil nomor undian untuk menentukan lawan robot yang akan bertanding.

c) Langkah 3: Peserta melakukan lomba robot dengan ketentuan robot yang paling cepat menuju titik akhir dialah pemenangnya.

d) Langkah 4: Pembagian hadiah bagi para pemenang juara lomba robot 1, 2 dan 3

e) Langkah 5: Penyerahan plakat kepada SMA Manbaul Ulum sebagai kenang-kenangan dan ucapan terimakasih.

\section{HASIL DAN PEMBAHASAN}

Kegiatan ini di lakukan selama 3 hari yaitu pada tanggal 10 - 12 Februari 2020 di SMA Manba'ul Ulum Pondok Pesantren Asshiddiqiyah Batu Ceper Tangerang Banten. Pelaksanaan Program Kemitraan Masyarakat berupa pelatihan robotic system dimana robot yang diganakan adalah jenis robot line follower. Dimana pelatihan ini diikuti oleh 30 orang santriwan dan santriwati dimana sebagai awal acara dibuka dengan sambutan dari perwakilan SMA manba'ul Ulum. Kegiatan PKM ini secara garis besar terbagi menjadi 3 agenda yaitu kegiatan pengenalan dasar system mikrokontroller, dimana jenis mikrokontroller yang kita gunakan adalah Arduino.

Para santri diajarkan komponen-komponen elektronika dan merangkai aplikasi sederhana tentang pengendalian lampu LED. Kemudian agenda kedua santri diajarkan lebih mendalam tentang aplikasi Arduino untuk pengendalian robot line follower. Diawali dengan perakitan komponen yang digunakan sampai dengan pembelajaran pembuatan program sendiri. Sehingga diharapkan santri bisa 
memodifikasi perintah pada Arduino dengan memodifikasi program yang mereka buat. Kemudian agenda terakhir adalah perlombaan robot Arduino yang telah para santri buat dengan peraturan apabila robot yang dijalankan sampai finish terlebih dahulu maka dialah yang akan menjadi pemenangnya. Disini santri di uji keterampilannya dalam memprogram Arduino sehingga mendapatkan setting kecepatan robot yang paling optimal.

Hasil kegiatan PKM dapat kita lihat pada beberapa faktor yaitu sebagai berikut:

a. Keberhasilan dalam hal pembuatan aplikasi Arduino. Hal ini terlihat pada saat para siswa melakukan perakitan dan pemrograman secara mandiri dan juga memodifikasi program dengan baik.

b. Adanya diskusi yang aktif dari para siswa, berupa pertanyaan tentang program dan komponen-komponen elektronika yang mereka buat

c. Tercapainya target materi yang disampaikan mencapai $90 \%$. Hal ini terlihat dari hasil kuesioner yang diberikan oleh Tim PKM mengenai isi materi dari para narasumber.

d. Antusiasme yang tinggi dari para siswa yang tergambarkan dari hasil kesan dan pesan yang kita tanyakan kepada para siswa agar melakukan pelatihan lanjutan di pondok pesantren Asshiddiqiyah 2.

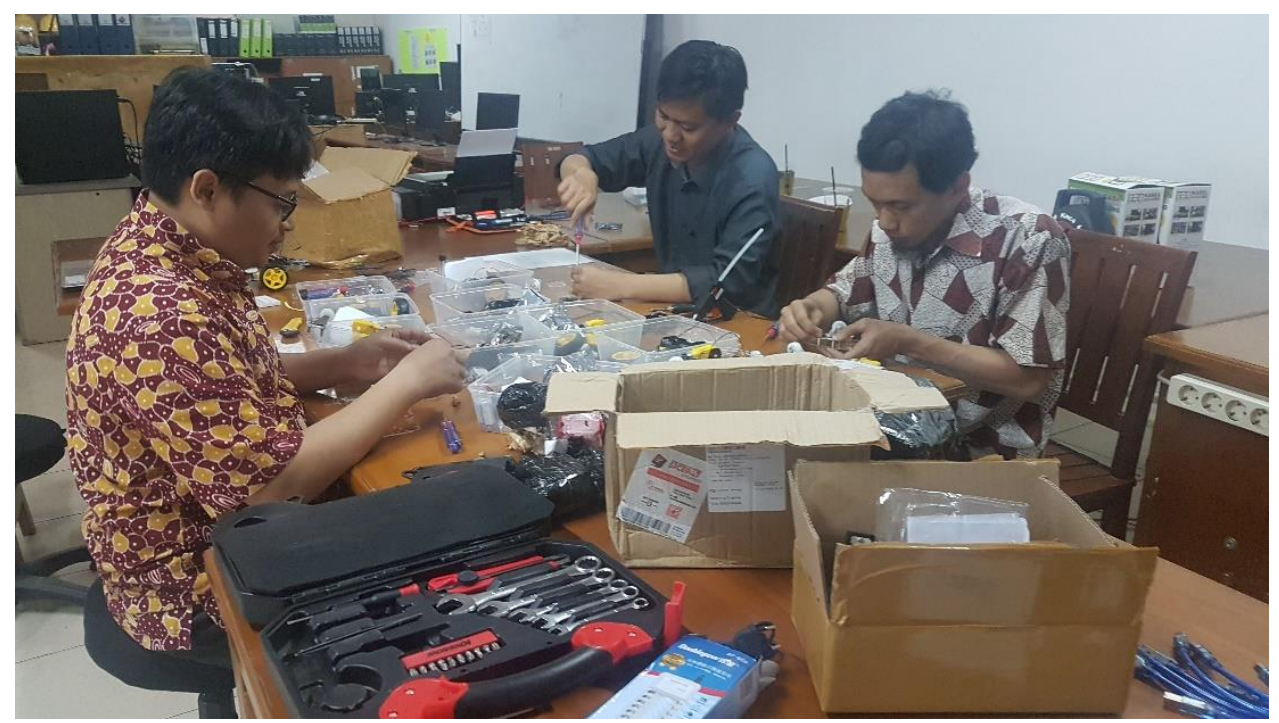

Gambar 2. Persiapan peralatan dalam rangka pengabdian masyarakat

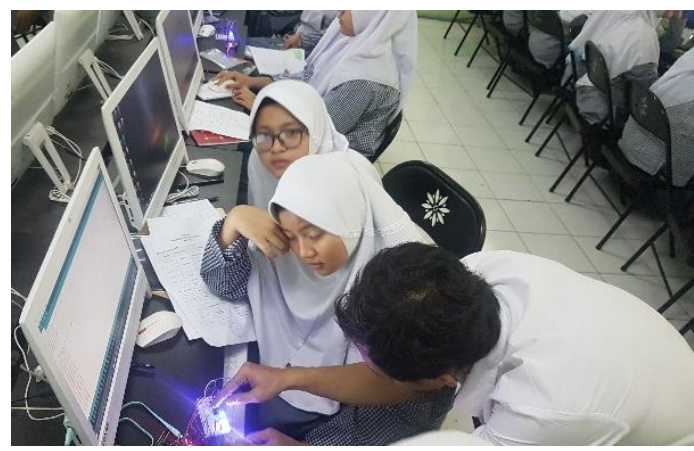

(a)

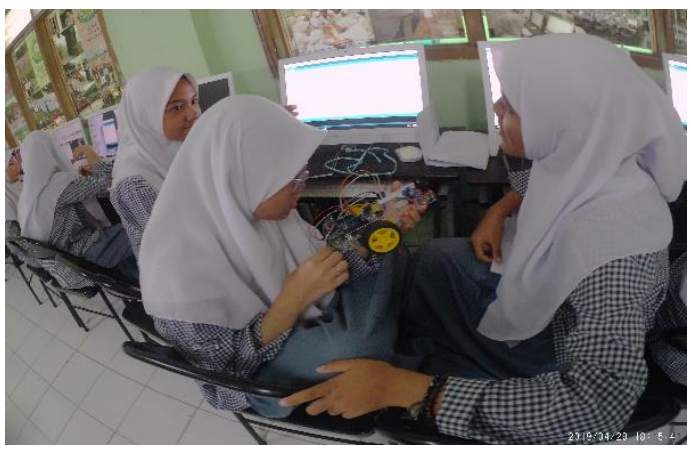

(b)

Gambar 3. (a) Proses perakitan dan programing lampu LED (b) Proses perakitan dan programing robot line follower 


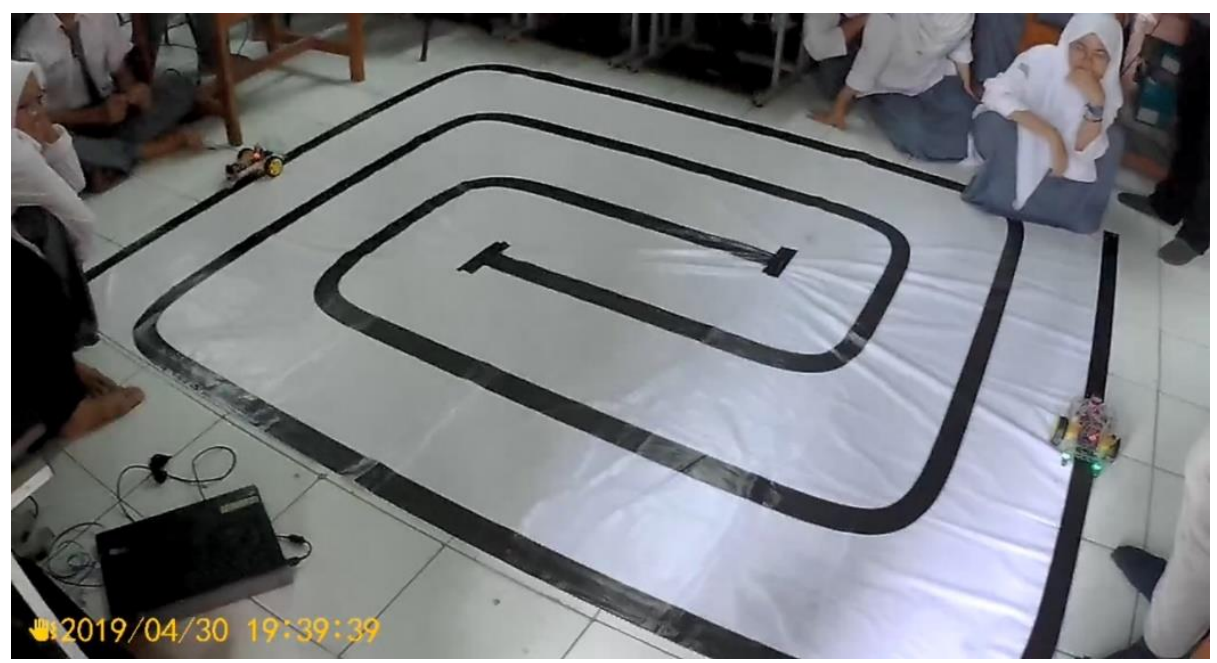

Gambar 4. Lomba robot line follower

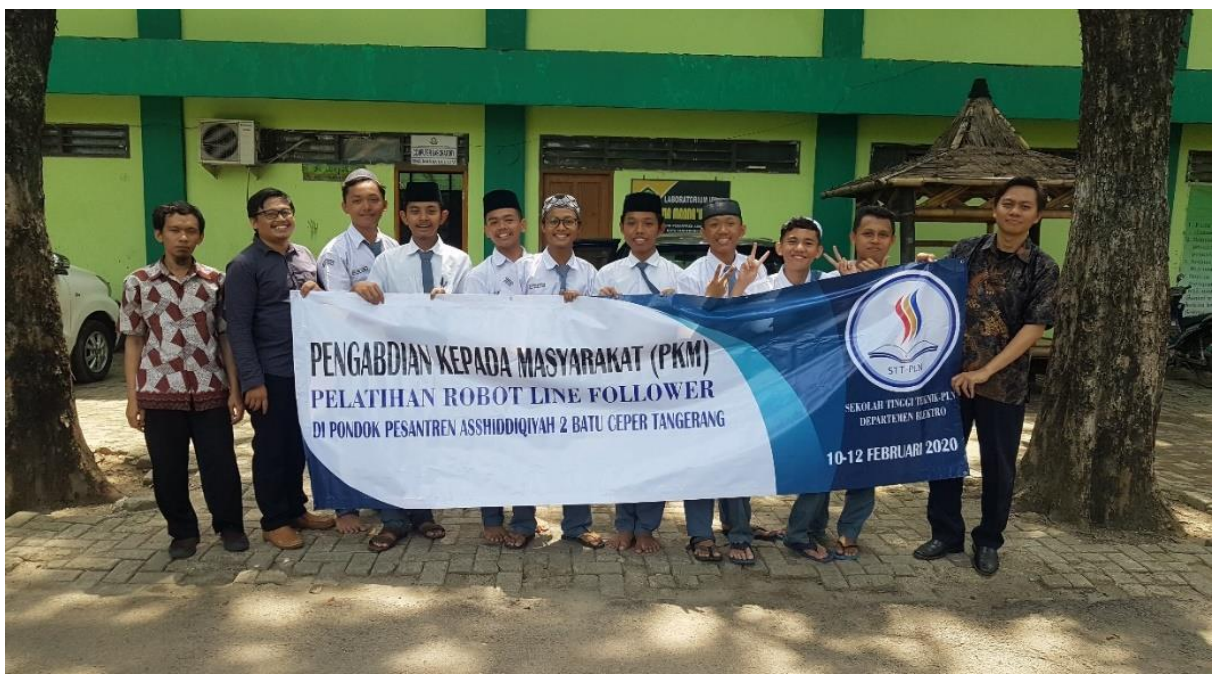

(a)

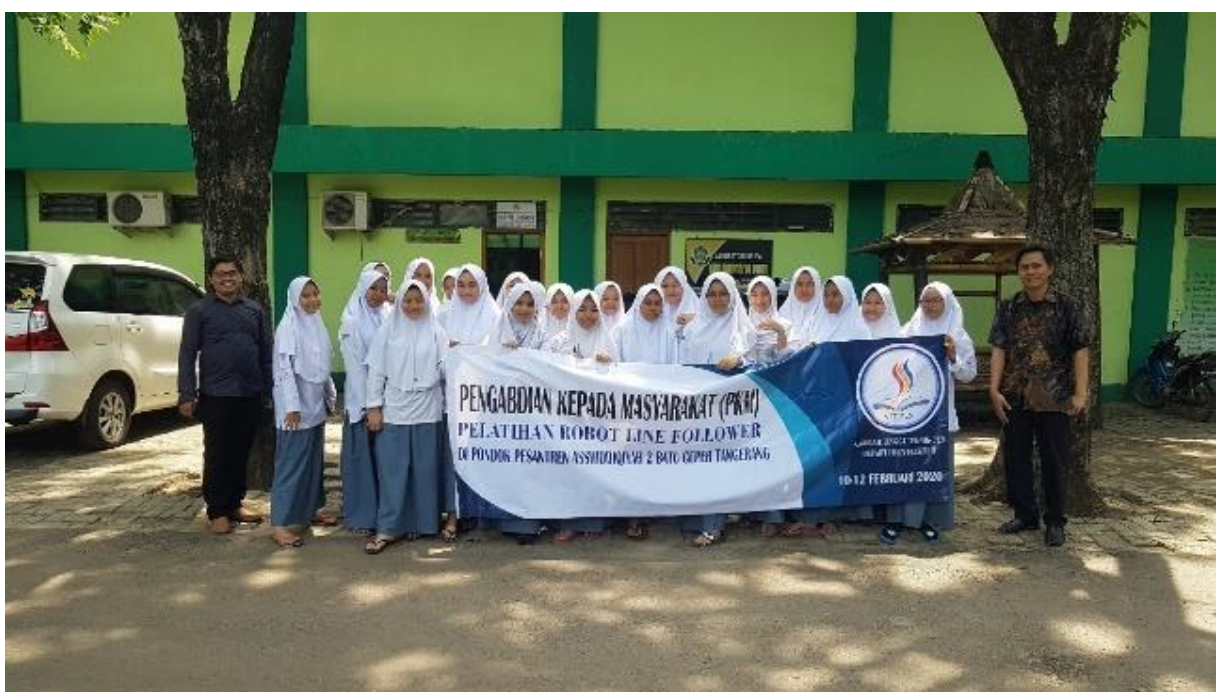

(b)

Gambar 5. Foto bersama setelah kegiatan berakhir (a) santriwan (b) santriwati 


\section{KESIMPULAN}

Adapun kesimpulan yang dapat diambil dari kegiatan ini adalah:

1. Kegiatan PKM atau program kemitraan masyarakat tentang pelatihan robot line follower mendapatkan respon yang sangat baik dari pihak sekolah

2. Kegiatan ini memberikan suatu hubungan langsung yang saling menguntungkan antara pihak kampus dan pondok pesantren.

3. Program PKM yang dilakukan selain membentuk hubungan langsung antara kampus dan masyarakat juga sebagai sumbangsih pada sekolah setempat guna meningkatkan ilmu pengetahuan dan teknologi terkini tentang robot sederhana.

\section{SARAN}

Berdasarkan kegiatan yang telah dilakukan, diharapakan Tim PKM dapat melakukan kegiatan pelatihan dengan berkesinambungan sehingga dapat dirasakan manfaatnya dan lebih meningkatkan pengembangan aplikasi Arduino tidak hanya pada robot line follower saja.

\section{UCAPAN TERIMA KASIH}

Penulis mengucapkan terima kasih kepada IT-PLN melalui LPPM-IT-PLN atas bantuan dana yang diberikan. Kemudian juga kepada pihak SMA Manba'ul Ulum Asshiddiqiyah 2 yang telah membantu sehingga kegiatan ini berjalan dengan lancar.

\section{DAFTAR PUSTAKA}

[1] Undang-Undang Darurat Republik Indonesia Nomor 20 Tahun 2003 (UUDrt/2003/20)

[2] David, Kendali Logika Fuzzy Pada Robot Line Follower, Pontianak, 2016.

[3] Susanto Hery, Robot line follower berbasis mikrokontroller AT89s51 sebagai media pembelajaran rancang bangun dan unjuk kerja robot beroda otomatis, yogyakarta, 2005

[4] Darmoko, A, Rancang Bangun Robot Line Follower dengan kendali PID berbasis mikrokontroller atmega 8535, Surakarta, 2011

[5] A. Kahe, "AVR Microcontroller", Nas Publication,2007

[6] P. Heyrati, A. Aghagani, "Science of Robot Disgn and Build Robot", Azarakhsh Publication, 2008.

[7] M. Mashaghi, "Robotic Guide", Kanone Oloum Publication, 2008.

[8] M.Zafri Baharuddin, "Analyst of Line Sensor Configuration for Advanced Line Follower Robot", University Tenaga Nasional. 